\title{
Cholic-2,2,4,4-D4 Acid
}

National Cancer Institute

\section{Source}

National Cancer Institute. Cholic-2,2,4,4-D4 Acid. NCI Thesaurus. Code C162163.

A deuterated form of cholic acid with potential diagnostic applications. Upon intravenous administration, cholic-2,2,4,4-D4 acid levels may be used to measure first pass hepatic extraction of cholate, which is influenced primarily by portal blood flow and portalsystemic shunt. 